\title{
Students' Understanding in Learning Fraction with Multiple Representations
}

\author{
S Widodo ${ }^{1}$, T Ikhwanudin ${ }^{2}$ \\ \{supri@upi.edu $\left.{ }^{1}\right\}$ \\ Universitas Pendidikan Indonesia, J1. Dr. Setiabudhi 229, Bandung 40154, Indonesia ${ }^{1,2}$, PPPPTK TK \\ dan PLB, Jl. Dr. Cipto No. 9, Bandung 40171, Indonesia ${ }^{2}$
}

\begin{abstract}
This research aims to analyse students' understanding when a fraction is taught with multiple representations. The respondents of this research were 27 junior high school students in the $7^{\text {th }}$ grade. The method of this research was qualitative, data were collected through the test, interview, and observation. The grounded theory with coding and constant comparison was used to analyzed data. The results of this research are two types of students' understanding, there are procedural understanding (syntax thinking) and conceptual understanding (semantic thinking). To justify the results, the research findings then discussed using related theories.
\end{abstract}

Keywords: Fraction, Understanding, Junior High School Student, Multiple Representations

\section{Introduction}

A fraction is taught commonly by the procedural way, students solved the problem of addition fraction by common denominator method. By the procedural way, based on Hiebert and Wearne, students just get procedural understanding or syntax thinking [1]. Students will not know any relation between properties in fraction problems, i.e. conceptual understanding (semantic thinking). According to Riccomini, teaching fractions using a number of lines and multiple representations has the potential for better results in students' performance [2]. Furthermore, Wynberg et al. conduct research that helps students understand fractions by using paper folding and number line [3].

There are some research findings on teaching fractions with multiple representations. First, the research that was conducted using geometry to make the representation of fractions [4]. Geometric forms represent fractions operation, i.e. addition, subtraction, multiplication, and division. They state that if teachers could use some colorful figures for the geometric representation, students will be more attracted to learn these concepts and learning fractions will be truly fun.

The second research was conducted by Clark and Roche [5]. They use a single game to teach fractions. They use an A3 version of the fraction wall, stuck to the board, and gather the class around to demonstrate. The third research was conducted by de Castro [6]. She uses picture representation in teaching fractions. For fraction multiplication model, firstly, students must identify multiplicand, for example $\frac{1}{3} \times \frac{2}{3}$, and then students draw representation with vertical divisions (shade the portion representing $\frac{1}{3}$ in rectangular figure). Secondly, students identify 
multiplier, in this example, $\frac{1}{2}$ is the multiplier, and then students draw representation with horizontal divisions. Thirdly, students superimpose the two rectangles, and then they count the double shaded region (numerator). Finally, students count the total number of regions (denominator), and then they represent product 1 as numerator and 6 as the denominator.

The fourth research was conducted by Scaptura, et al [7]. They use art to teach fractions. In this representation model, students recognize fractions by identifying the colored portions of a grid from their own design. Students construct their own art design by gluing small colored paper square on a grid. For this research lesson, researchers use a grid of 100 squares so that students could clearly visualize the decimal form (0.01 for each square). Students could then calculate their fractions. This square on-grid model is inspired by an American artist Ellsworth Kelly, a twentieth-century painter who is popular for his contribution to abstract art.

The fifth research was conducted by Mendiburo and Hasselbring [8]. They use technology to teach fractions and find that manipulative technology (computer) in teaching fractions is just as meaningful as teaching fractions with physical manipulative. This research was conducted at a charter middle school in Tennessee for 5-8-grade students. Firstly, students are given preassessment by the researchers to know their prior knowledge of fractions. This diagnostic assessment was done with a software computer. Secondly, researchers conduct intervention within 10 Days. On Day 5 and Day 10 of the intervention, students complete a paper and pencil assessment based on material in the intervention using their physical or virtual fraction kits. Finally, students do exercise and games on each day of instruction.

Multiple representations are very important in fraction learning. According to Lesh, Posh, and Behr students gain a deeper understanding of a concept when they can identify and model a mathematical concept in various representation systems and have the flexibility to move from one representational system to another [9]. In addition, Principle and Standards for School Mathematics (NCTM 2000) encourages students to represent their mathematical ideas so that it makes sense to them, even though their representations are not conventional. Therefore, in this paper, we would like to discuss students' understanding of learning fractions with multiple representations.

\section{Methods}

The method of this research was qualitative, used a case study with single-case (holistic) designs [10]. The method is used to describe findings related to the research problem formulation, i.e., how students' understanding in learning fractions with multiple representation.

The respondents of this research were 23 students in 7 th grade in a Junior High Inclusion School in West Java, Indonesia. Students work on research instruments, then their work was analyzed to evaluate their types of understanding. Students used image representation, real world context, writing symbols and verbal symbols from class VII mathematics textbooks of the Ministry of Education and culture [11].

The test instruments used in this study are as described in Table 1 below: 
Table 1. The test instruments.

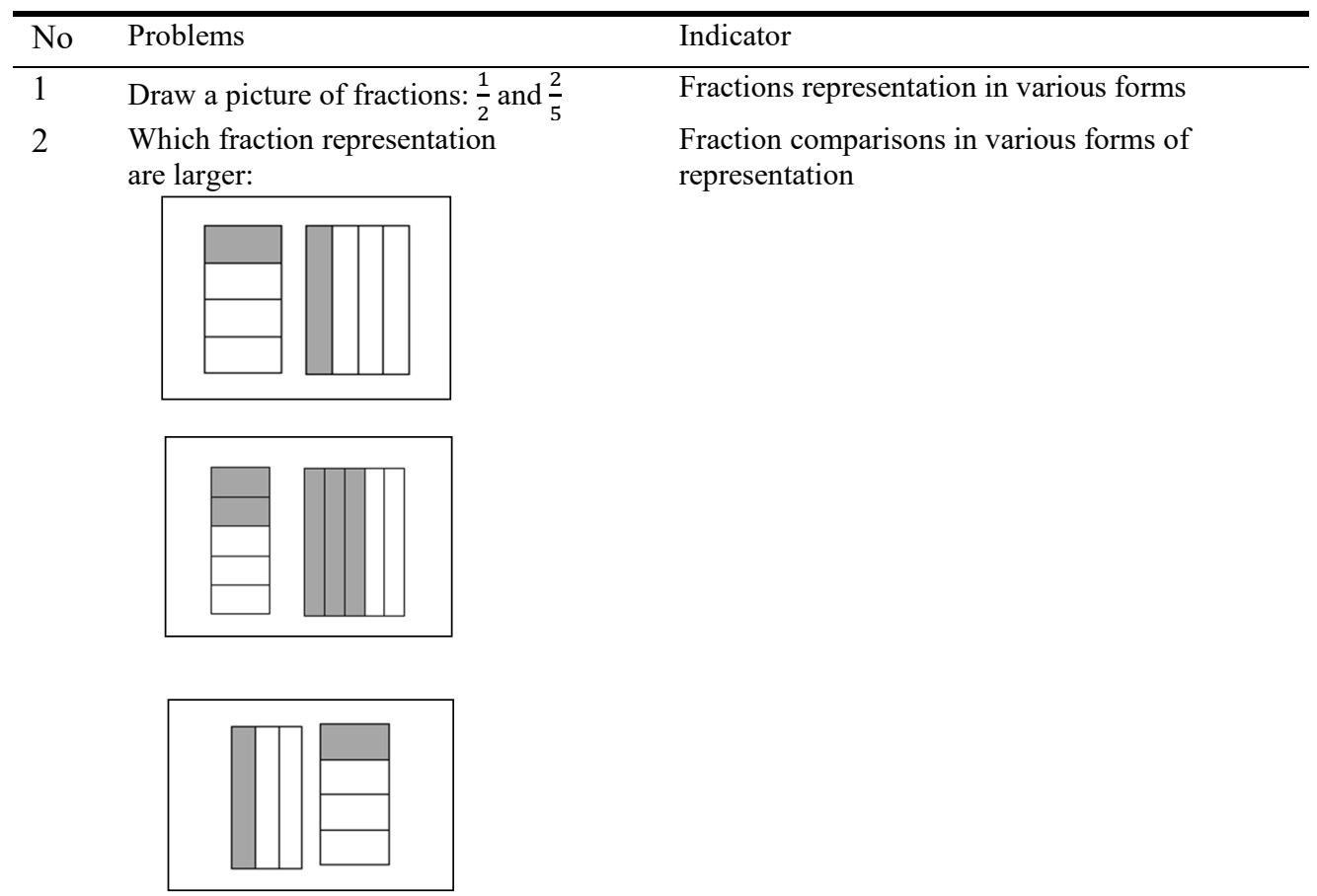

3 a. Which one is larger: $\frac{1}{2}$ or $\frac{2}{3}$

Fraction comparisons

b. Which one is larger: $\frac{2}{3}$ or $\frac{3}{4}$

4 How to find two fractions which are equal $\frac{1}{2}$ ?

5 Solve the problem below:

$\frac{1}{3}+\frac{1}{3}=$

$\frac{1}{3}+\frac{1}{2}=$

Fractions equalities

The addition operation of fractions

6 Solve the problem below:

$\frac{4}{5} \times \frac{1}{3}=$

The multiplication and division operation of fractions

$\frac{9}{4} \div \frac{3}{5}=$ 


\begin{tabular}{lll}
\hline No & Problems & Indicator \\
\hline 7 & Rani ran $\frac{2}{5} \mathrm{~km}$ on Monday, and on & Fractions in a word problem \\
& Tuesday she ran $\frac{3}{7} \mathrm{~km}$. How many $\mathrm{km}$ & \\
& she ran on both days?
\end{tabular}

The instrument above has been used in the research on evaluating students' understanding of fractions in the inclusive school [12]. Validation of this instrument has been conducted by external experts. At the end of the learning session based on the Indonesian national curriculum, students work on the instrument. The instrument indicator is based on the fraction topic that has been studied by students.

\section{Result and Discussion}

\subsection{Conceptual Understanding}

Figure 1 describes the student's answer that uses conceptual understanding. The problem is which fraction representation image is larger. There are three images. We evaluate that students understand the problem and answer it using conceptual understanding.

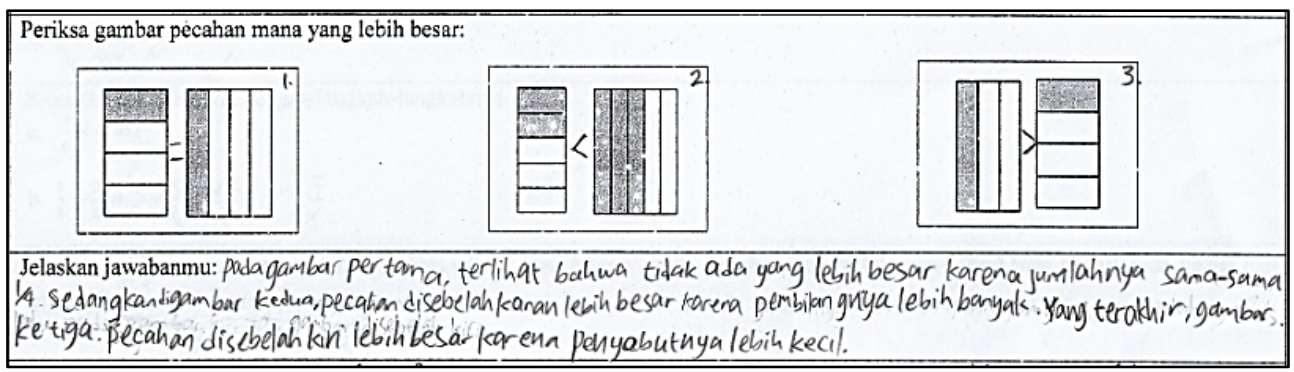

Fig. 1. Student answer example on conceptual understanding.

In Figure 2, the problem is which fractions are larger between $\frac{1}{2}$ and $\frac{2}{3}$. The student's answer used the image to concretize her thinking that $\frac{2}{3}$ is larger than $\frac{1}{2}$. We evaluate that student's understanding is conceptual.

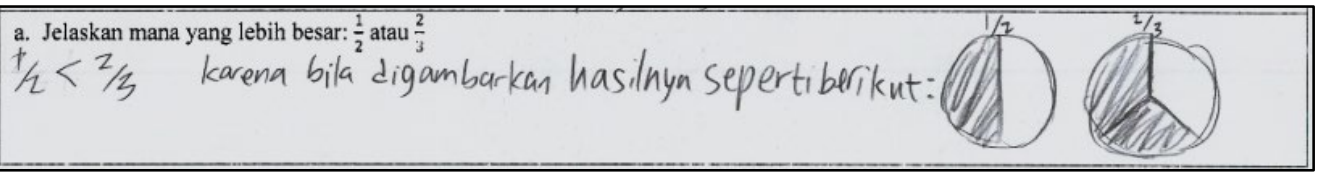

Fig. 2. Student answer example on conceptual understanding. 


\subsection{Procedural Understanding}

In Figure 3, the problem is fractions addition word problems. We evaluate that the student does procedural understanding by using fractions addition procedure to complete fractions word problem.

Susi berlari $\frac{2}{5} \mathrm{~km}$ pada hari senin. Pada hari selasa, Susi berlari $\frac{3}{7} \mathrm{kn}$. Jelaskan berapa kilometer $(\mathrm{km})$ Susi berlari pada kedua hari
tersebut? $\frac{2}{5}+\frac{3}{7}=\frac{14+1 \mathrm{~s}}{35}=\frac{29}{35} \mathrm{~km}$

Fig. 3. Student answer example on procedural understanding.

We find another example of students' procedural understanding, in Figure 4the problem is how to find two fractions that equivalent to $\frac{1}{2}$. We evaluate that the student does the procedural understanding by multiplying the first fraction with two and the second fraction with three. Fractions $\frac{1}{2}$ become $\frac{2}{4}$, and $\frac{1}{2}$ become $\frac{3}{6}$.

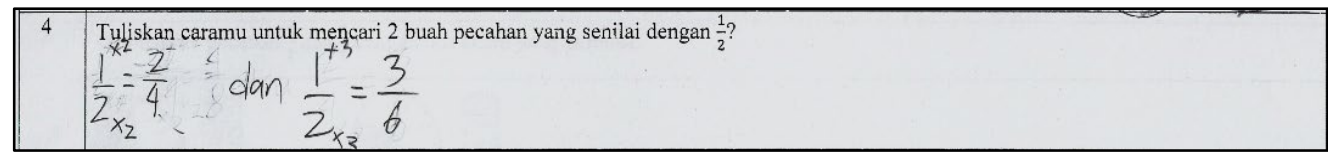

Fig. 4. Student answer example on procedural understanding.

To sum up, we find two types of understanding, there are conceptual and procedural understanding. In other terms, Skemp called conceptual understanding with relational understanding, which is to associate something with other things correctly and be aware of the process carried out [13]. Furthermore, Skemp also mentioned procedural understanding as instrumental understanding, that is memorizing something separately or being able to apply something to a routine/simple calculation, doing something algorithmically only [13].

\section{Conclusion}

In our result, there are two types of students' understanding, procedural understanding (syntax thinking) and conceptual understanding (semantic thinking). When the teacher teaches the concept of the fraction to students, the results of this study can be used as one of the didactic anticipations, that is how to make students gain more conceptual understanding 


\section{References}

[1] Hiebert, J., Wearne, D.: Procedures over concepts: The acquisition of decimal number knowledge. In J. Hiebert (Ed.). Conceptual and procedural knowledge: The case of mathematics. Lawrence Erlbaum Associates, USA (1986)

[2] Riccomini, P. J.: Core issues of math: number sense and fraction. Kansas MTSS Symposium 2010 (2011)

[3] Wyberg, T., Whitney, S. R., Cramer, K. A., Monson, D. S., Leavitt S.: Unfolding fraction multiplication: Helps students understand an important algorithm by using a piece of paper and a number line. Mathematics Teaching in The Middle School. pp. 289-293 (2012)

[4] Dey, K., Dey, R.: Teaching Arithmetic of Fractions Using Geometry. Journal of Mathematics Education. pp. 170-182 (2010)

[5] Clarke, D., Roche, A.: The power of a single game to address a range of important ideas in fraction learning. The Australasian Mathematical Psychology Conference 2010 (2010)

[6] de Castro, B. V.: Cognitive models: The missing link to learning fraction multiplication and division. Asia Pacific Education Review. pp. 101-112 (2008)

[7] Scaptura, C., Suh, J., Mahaffey, G.: Masterpieces to mathematics: Using art to teaching fraction, decimal, and percent equivalents. Mathematics Teaching in The Middle School. pp. 24-28 (2007)

[8] Mendiburo, M., Hasselbring, T.: Technology's impact on fraction learning: An experimental comparison of virtual and physical manipulative. SREE Conference Abstract Template (2011)

[9] Lesh, R., Post, T., Behr, M.: Representations and translations among representations in mathematics learning and problem solving. In C. Javier (Ed.) Problem of representation in the teaching and learning of mathematics. Lawrence Erlbaum Associates, USA. pp. 33-40 (1987)

[10] Yin, R. K.: Case study research: Design and methods. Sage, USA (2009)

[11] Kemdikbud: Matematika kelas VII. Kemdikbud (2016)

[12] Ikhwanudin, T., Suryadi, D.: How students with mathematics learning disabilities understands fraction: A case from the Indonesian inclusive school. International Journal of Instruction. pp. 309-326 (2018)

[13] Skemp, R. R.: Relational understanding and instrumental understanding. Mathematics Teaching. pp. 20-26 (1976) 